\title{
Views on Leadership and Competence among Formal Leaders in Care of Older Adults: Differences Over Time
}

\author{
Karin Blomberg*, Ulla Olsson, Inger James and Annica Kihlgren
}

School of Medical and Health Sciences, Örebro University, Örebro, Sweden

\begin{abstract}
Background: Leaders play an essential role in the health care of older adults. The leadership role has changed over the years because of new demands in providing care for older adults with multiple chronic conditions, as well as a lack of resources.

Aim: The aim of this study was to describe formal leaders' views over time on their leadership and the competence among staff in care of older adults.

Method: Individual interviews and focus group discussions with leaders in care of older adults were conducted with a total of 46 formal leaders in $2000(n=20)$ and $2011(n=26)$. The analysis took a qualitative approach, using interpretative description.

Results: The leaders' descriptions of leadership encompassed two different views on leadership over time, from "I as a leader" to "We together". The leaders interviewed in 2011 saw practical wisdom (phronesis) as a central aspect of staff competence. Throughout the interviews, a greater focus on personal characteristics was seen over time.

Conclusions: Differences over time in views of the leaders' role and staff competence, especially the increased focus on personal characteristics, may have an impact on the health care provided to older adults. This is particularly true if formal education is not prioritized. Strategies within organizations and continuing development and education must take these changes into consideration.
\end{abstract}

Keywords: Competence; Focus groups; Interviews; Leadership; Management; Older adults

\section{Introduction}

Leaders play an essential role in the health care of older adults. The leadership role has changed over the years because of new demands in providing care for older adults with multiple chronic conditions, as well as a lack of resources [1]. Knowledge is lacking about the kind of expertise and leadership that is necessary to meet the vision of highquality care for older adults. The current research on leadership in care of older adults has mainly focused on both the leaders and the led, and their interaction. Therefore, this study focuses on leaders' views over time on their leadership and competence among staff in care of older adults.

\section{Background}

Health care organizations worldwide are undergoing rapid and often radical changes. Care of older adults has historically been described as "low status" [2], with consequences such as decreasing interest in working in care of older adults. Such changes can lead to critical issues, especially when the need for competent staff is likely to increase. The number of formal leaders in community care during the past decade has declined, with the result that fewer leaders are now responsible for an increasing number of staff. Furthermore, leaders in community care often have large groups of staff with inadequate skills, which can lead to failure to meet national and local targets for health care. They also have insufficient administrative assistance. One significant problem is the difficulty of recruiting and retaining personnel with formal education [3]. Among those working in care of older adults in Sweden today, nurses' assistants make the largest group, with registered nurses numbering only a few. Physicians, usually general practitioners employed by the county council, often function as consultants [4].
The way in which formal leaders in care of older adults today perceive and practise their leadership is not an isolated phenomenon, but can be considered as a reflection of the prevailing societal view on leadership and management [5]. Today's form of democracy requires the active participation of individuals, which is one of democracy's basic principles. Our society's deliberative model of democracy is characterized by an increasing number of decisions being made closer to the people, in a process of collaborative decision-making through deliberative conversation [6,7]. Working life is based on a similar foundation, which can be expressed in terms of leadership and teamwork as the basis for collective action. Collective action requires a common vision, which is a common basis for practice being carried out. This could for example be achieved by including teamwork, which is based on dialog and cooperation [8].

There is a diversity of literature on leadership, but in general the development of leadership in contemporary society has moved from a more authoritarian style of leadership to a more democratic style with goals and visions [9-11]. Leadership seen as an act is taskoriented, while leadership viewed as a relationship is focused on interaction, communication, and reciprocity between leaders and their employees $[9,12]$. There are two types of relational leadership.

*Corresponding author: Karin Blomberg, School of Health and Medical Sciences, Örebro University, S-70182 Örebro, Sweden, Tel: +46-19-30 12 70; E-mail: karin.blomberg@oru.se

Received July 24, 2013; Accepted October 08, 2013; Published October 12 2013

Citation: Blomberg K, Olsson U, James I, Kihlgren A (2013) Views on Leadership and Competence among Formal Leaders in Care of Older Adults: Differences Over Time. J Gen Pract 1: 126. doi: 10.4172/2329-9126.1000126

Copyright: @ 2013 Blomberg K, et al. This is an open-access article distributed under the terms of the Creative Commons Attribution License, which permits unrestricted use, distribution, and reproduction in any medium, provided the original author and source are credited. 
The first is transformative with a clear focus on ethical issues; this is a form of moral leadership. The second is transformational, or as it has more recently been called, emotionally intelligent leadership [13]. The transformational leader can use charisma to generate opportunities and bring changes, by creating opportunities for empowerment of the employees [11,14]. Both transformative and transformational leadership emphasize the relationship between the leader and employees, and the relationships between the employees in the organization [13]. Today it is essential to supplement leadership with ethical values such as development of core values for leadership and management [15].

The task of leading employees is a complex one, and so the leaders of today need to adapt their leadership and exert situated leadership $[16,17]$. In the public sector, leadership is often about both leading the service and leading the staff. For example, in health care, leadership often involves leading both patient-directed care and the staff [18]. Leaders play an essential role in care of older adults, and their role has expanded over the years. They have greater responsibility, which includes decision making, planning, and working in an environment with decreasing resources. Skilled leaders and skilled personnel are central to the provision of care for older adults with multiple chronic conditions, but knowledge is lacking about the kind of expertise and leadership that is necessary in the care of older adults. There is a need for increased knowledge and better understanding of formal leaders' views, as well as whether these views have changed over time, between 2000 and 2011. Therefore, the aim of this follow-up study was to describe leaders' views over time on their leadership and the competence among staff in care of older adults.

\section{Method Design}

The present study has a descriptive qualitative design. This followup study included interviews, individual interviews [19], and faceto-face focus group discussions (FGDs) [20] with formal community leaders in order to describe similarities and differences over time in their views on leadership and competence. Data collection took place on two occasions, one in 2000 and one in 2011.

\section{Sample and Settings}

The participants were all formal leaders in care of older adults in a central Swedish county. The leaders were selected strategically; all had more than five years' experience of working as a formal leader, but they differed in terms of educational background (formal competence in nursing or home care service). The samples were chosen in order to achieve variation.

In 2000, two primary health care centres (PHCC) were chosen (numbered 1 or 2), each serving a specific area in the same county. All the leaders in respective PHCC were alphabetically listed and the first ten formal home care service leaders in PHCC 1 were invited to participate. From PHCC numbered 2, ten formal leaders with nursing backgrounds were recruited in the same manner.

In 2011, 26 formal leaders with home care service $(n=16)$ or nursing $(n=10)$ backgrounds were strategically selected from the same county. Ten of these leaders were invited for an individual interview and 16 for two FGDs, according to their own wishes. In total, the study included 20 formal leaders in 2000 with home care service or nursing backgrounds and 26 formal leaders with the same background in 2011. The leaders were aged between 44 and 60, and almost all were women $(n=43)$, the exceptions being three men with nursing backgrounds.

\section{Data Collection}

All individual interviews in 2000 and in 2011 were carried out by the fourth author and took place, in accordance with the wishes of the interviewees, at their place of work. To gain a deeper understanding of the leaders' views on leadership and competence among caregivers, open interviews [19] were conducted. The FGDs in 2011 followed the standard procedures for FGDs [20], and each was led by an experienced moderator (the first, third, and fourth authors). The interviews and FGDs were recorded with the participants' permission, and lasted 60 90 minutes.

On both occasions, the leaders were asked the same question at the start of the interviews and FGDs. The leaders were encouraged to speak as freely as possible about their leadership and the competence among the staff in care of older adults. Follow-up questions were "Please tell me more about that" or "What do you think about that?" An experienced secretary transcribed all interviews verbatim.

\section{Data Analysis}

All the transcripts from both the individual interviews and FGDs were read repeatedly to obtain a sense of the data as a whole. The analyses originated from interpretative description [21], a qualitative inductive approach to obtain clinically useful knowledge and understanding. First, data on the leaders' descriptions of leadership and competence among staff in elderly care were sorted into groups, resulting in a preliminary categorization scheme. In the next step, we divided the interviews into two groups, one with the interviews from 2000 and one with those from 2011, and then analysed these groups in relation to each other, looking for similarities and differences between these data. Questions like "How do the leaders describe their work in 2000 and in 2011?" were asked in order to find similarities and differences in the text. Two different themes were identified across the data, with subthemes describing similarities and differences over time. All authors discussed and validated the preliminary findings. Quotations are presented below to illustrate the findings, having been translated from Swedish to English by an authorized translator. Hesitations and unnecessary words are indicated by ellipses (...), and comments from the authors are placed in square brackets.

\section{Ethical Consideration}

Permission to interview leaders in elderly care in 2000 was granted by the secretary of the Regional Research Ethical Committee [22], and the participants gave their informed consent. When interviewing the leaders 11 years later, we were granted approval by the Regional Research Ethical Committee (registration number 2011/009). The leaders were not regarded as dependent on the interviewer in any way, and could decline participation in the study at any time without giving a reason.

\section{Results}

The leaders described their views in terms of both visions of leadership and descriptions of how they acted in the role of leader in care of older adults. The results show that, over time, the leaders' descriptions encompassed two different views on leadership. This can be interpreted as a view of leadership changing from "I as a leader" to "We together". Finally, the results also revealed a different focus of the leaders' view on competence among staff: "A greater focus over time on personal characteristics". 


\section{Theme 1: Visions of leadership and being a leader in care of older adults}

Sub-theme: "I as a leader": The descriptions of the visions of leadership included mention of the salient goal of putting the goals of care of older adults first, before the leaders' goals. It was the leaders' responsibility to develop and conduct quality assurance of care. The leaders described how they became involved in developing the health care unit to ensure that the care was as good as possible. For example, this might entail doing analysis on the frequency of the number of patients, reasons for admission, and occupancy as a basis for a tool for staff to work with. The leadership included motivating the staff to do their job better, and drawing attention to the work the staff had done and the developments their team had undergone. Budgeting and planning were also central responsibilities of the leader. One leader said:

I will be the one who provides quality assurance and follows up on the activities... you have to be the one who's the driving force...

Much of the leadership was about co-ordinating, and ensuring that there was enough staff with the right skills. This was explained as follows:

...that there are enough personnel, enough trained personnel at the right time, and they have to co-operate optimally... Then I have to link it together to the skills I have today...

To be the solitary leader was also clear from the leaders' descriptions of the municipal view on leadership in care of older adults. The work was the responsibility of the leader, and as a consequence, being a leader was experienced as stressful and pressured. As one leader expressed it:

I have to be the face of the activities, I have to encourage others to be enthusiastic, I have to keep spirits up.

The leader also provided guidelines and information to the staff, and educated them. Other tasks included observing staff, controlling their work, and defining their duties, as well as being a problem solver and finding solutions.

I try to talk about the planning so the staffs know what they are working towards.

Another task described by the leaders was to give the staff positive feedback and thus make them positive about their work. This was exemplified by one leader who responded to the question of what leaders in care of older adults do:

...praise them, tell them you're really doing a great job and you're doing really well...

Sub-theme: "We together": The visions of leadership described by today's leaders centred on the team and collaboration within the team as a central point of leadership. The leader was no longer seen as a sole actor. Some leaders described this using the term "closeness leadership". Closeness leadership was described as meeting and following the staff, conversing with everyone, being responsive to issues that came up, and being available to help. The team and the "we feeling" in discussions between the leader and his or her team was described by one leader as follows:

But not personally [as leader] I can't run around everywhere, so I have to bring my nurses with me ... so we are a team that discuss how are we going to do this? How do we work with this?

It was considered important to get everyone on the team to acknowledge the staff's different learning possibilities based on each individual's ability and needs. The opportunity to discuss and reflect was also seen as central within the team.

... need to have conditions to bring together discussions, reflections an opportunity to think about where we are in our activities.

It was also described as important to always have the staff's wellbeing in mind. Doing follow-up was seen as necessary not only in the provision of health care, but also for the wellbeing of staff members. It provided them with confirmation and gave the opportunity to let every member of staff become visible and feels involved. The leaders made requests for more money, for the purpose of investing in the staff. In their descriptions of being a leader, the leaders highlighted the team and their participation. For example, one said:

... they are the ones who decide ... personally, I sit in on all of the [work] groups, but they are the ones who do the job, they are the ones who have the floor...

\section{Theme 2: Views on competence of staff in care of older adults}

Sub-theme: "A greater focus over time on personal characteristics": The results showed differences over time in the leaders' views on competence of staff in care of older adults. The leaders interviewed in 2000 said that staff should be trained and qualified to a greater extent than the leaders interviewed 11 years later. One leader expressed:

The staff needs professional competence... a formal education basically.

When recruiting new staff, they considered it important that these staff should have basic competence together with openness to ideas, willingness to take responsibility, flexibility, the ability to cooperate, a good attitude, and a view of the older adult's family as a resource. Education was also seen as a way to increase the status of the profession and attract more young people to care of older adults. The leaders in 2000 described how they as leaders focused on internal training for their staff. These leaders argued for further education. One leader argued:

There is low competence in care of older adults today, it require higher skills really...

This was in contrast to the leaders interviewed in 2011, which in a greater extent emphasized personal competence as essential in care of older adults. These leaders said that formal education is not "the whole thing". One leader expressed:

It doesn't matter how much education or training a person has, it's more a matter of common sense and taking it easy and methodically, and not stressing out. So it isn't just education.

The leaders interviewed in 2011 considered practical wisdom to be a central aspect of staff competence in contrast to the previous interviews. Formal education was viewed as something you could always get; people would always be able to acquire formal knowledge. One leader argued that values cannot be learned:

... personal qualities, because you can always learn and acquire assistant nurse skills, but the rest of it you can't learn..

These leaders saw personal characteristics, such as attitude and behaviour, as being much more significant for the care.

A requirement or wishes we have is that there will be educated staff. Although it is not always what you need...there are many uneducated 
that fits very well in health care and there are many educated that do not fit, despite formal competence.

\section{Synthesis}

The interviews revealed differences and similarities over time in the formal leaders' view on their leadership and on staff competence. In the interviews conducted in 2000 , the metaphor "I as a leader" was noticeable. This view could be seen as a task-oriented leadership, where the formal leader was described as the only one who should ensure the quality of care and take responsibility for the work situation of the staff. The later interviews, on the other hand, revealed a different view. "We together" included descriptions of the importance of teamwork and collaboration with the staff. This could be seen as a relational leadership. However, one pattern that persisted over time was the leaders' perception of themselves as role models in attitude and approach. The formal leaders' views on competence among their staff also showed, over time, a greater focus on personal characteristics, with practical wisdom (phronesis) being seen as central.

\section{Discussion}

Today's leaders described increased comfort and security in their role, as they were able to let the staff have an influence on their work. The leaders' views on leadership had developed from seeing themselves as alone in carrying and developing the unit, and pointing with their "whole hand" to show their staff the way forward, to being leaders who find alternative ways forward as a team effort with their coemployees. The role of being leader has changed from being a "guide" to being "someone who searches for ways". This change over time is seen in several studies $[11,13,15,17]$. The employees can be seen as cocreators of the leadership [12]. Today's leaders described the team as a cornerstone, and said that the leader belongs to the team. This could be interpreted as leadership focused on relationship [11,23,24], with mutuality between the leader and staff both at the individual and at the group level. This was expressed in the term "closeness leadership" used by one leader, which is in line with a transformational or emotionally intelligent leadership [13]. The leaders of today emphasized the significance of the team and collaboration with and between the staff. This can be seen in the light of today's trends in societal and work life, where trans-boundary collaboration and teamwork are highlighted as success factors for effectiveness, productivity, and good quality (in our case, in patient-directed care). Leadership has been described as having an obvious effect on the quality of care $[25,26]$. Wong and Cummings [25] reported lower patient mortality, increased patient satisfaction, and fewer patient events in units with transformational leadership. However, the question is whether this change in style of leadership could have other impacts on patient outcomes. This must be further investigated.

One pattern that persisted over time was the leaders' perception of themselves as role models in attitude and approach. How a leader responds and relates to the staff is reflected in the staff's attitude and approaches to the older adult [27]. Today's leadership in care of older adults is complex; leaders both lead and participate in close care work, and are also involved in other complex leadership roles, and consequently perform a dual leadership role. Sørensen et al. [28] argue that it is important for leaders in health care to be active in clinical practice and to be clinical leaders in parallel with providing leadership. The question is whether dual leadership challenges the leader's position as a leader, or whether it is only what Wilhelmsson [29] calls "joint leadership".
In terms of the leaders' views on competence, the results show that it is not always education that determines whether a member of staff is competent or not. Competence is much more about "common sense", according to these leaders. Common sense can be considered as a form of knowledge such as practical wisdom (phronesis) [30], meaning the ability to act judiciously, a result also supported by Cook and Leathard [31]. The leaders in this study felt that education gave status, but that the practical work and the encounter with the older adult often involved "knowing how instead of just knowing that" [32]. The leaders were looking for more artistry in professional practice, applying tacit knowledge [33] or practical wisdom [30].

Reflection is essential for development of competence, according to the leaders interviewed. If the staffs are to be able to reflect over their work, the leaders must lead by good examples and with a reflective approach. Patrick et al. [14] showed that the leaders' role as a model and their approach when acting in different situations were reflected in the staff's approach and way of acting. This means that if the leader shows that reflection is important, the staff will prioritize reflection in their work. To become a reflective practitioner [34] takes time. The staff must be flexible enough to reflect as a team, but reflection must also be done by single staff members on their own, despite shortage of time and personnel. Care of older adults has been characterized for years by a lack of well-educated personnel and difficulties in retaining personnel [35]. This is compounded by an insufficient number of young people choosing the relevant educational programmes [3]. There are significant risks connected to the fact that today's leaders do not consider formal qualifications to be central for competence in care of older adults. If employees in this public sector undergo less training and education, and are less well qualified, how can care of older adults be guaranteed to be both safe and high quality? It is well known in the Swedish context that the incidence of reports of incorrect care and treatment as well as other inconveniences increases in care of older adults [3].

\section{Methodological Considerations}

Longitudinal qualitative research raised methodological difficulties due to changes in the society, the care of older adults, as well as the changes in the study population during the time. If we had conducted interviews on repeated occasions with the same leaders, we may have been able to provide a deeper and probably a more multifaceted picture of leaders view on leadership and staff competence. Differences in the leader's educational and professional background may have influenced how they spoke about their leadership and competence. However, together with the fact that they worked in different municipalities and had different experiences as leaders, this could be seen as strength of the study, since it provided the opportunity to capture a wide spectrum of views. To ensure trustworthiness the findings, methodological considerations have been taken into account related to principles described by Lincoln and Guba [36]. To ensure credibility as well as dependability, several steps have been taken. Different data collection methods (individual interviews and FGDs) were used to obtain data with both depth and breadth, and could see as complementary, or as triangulation of different data sources to strengthen credibility [21,37]. Although they cannot be generalized due to the qualitative design, our findings are credible if people with similar experiences can recognize the descriptions or the interpretations as their own [38]. In this way, the results can be transferred to similar situations. Discussions between the authors took place during the analyses to ensure the credibility of the results, and a high level of agreement could be demonstrated. 
Citation: Blomberg K, Olsson U, James I, Kihlgren A (2013) Views on Leadership and Competence among Formal Leaders in Care of Older Adults: Differences Over Time. J Gen Pract 1: 126. doi: 10.4172/2329-9126.1000126

\section{Conclusion}

This study describes differences and similarities over time in leaders views' of their leadership and the competence among staff in care of older adults. Today's leaders described a "closeness" leadership, which sees the staff as co-leaders. However, the leaders' greater focus on personal characteristics in their views of competence among staff must be further investigated. The differences of views of leaders' role and competence, and especially the increased focus on personal characteristics may have an impact on the health care provided to older adults. This is particularly true if formal education is not prioritized. Strategies within organizations and continuing development and education must take these differences into consideration.

\section{Acknowledgement}

We thank all the leaders who participated in the interviews and the FGDs and generously shared their perspectives with us. Funding has been gratefully received from Örebro University. The authors report no conflicts of interest. The authors alone are responsible for the content and writing of this article.

\section{References}

1. Swedish Ministry of Health and Social Affairs (2010) Proposals by the Council for Legislation: Dignity in elderly care.

2. Brown A, Draper P (2003) Accommodative speech and terms of endearment: elements of a language mode often experienced by older adults. J Adv Nurs 41: 15-21.

3. The National Board of Health and Welfare (2012) The condition and development in health care and social services. Report 2012-2-2.

4. SALAR The Swedish Association of Local Authorities and Regions (2006) Care of the elderly in Sweden today.

5. Held D (1996) Models of democracy. Polity Press, Cambridge, USA

6. Benhabib S (1996) Toward a deliberative model of democratic legitimacy. In: Benhabib S (eds) Democracy and difference. Contesting the boundaries of the political. Princeton University Press, New Jersey, USA.

7. Cohen J (1996) Procedure and substance in deliberative democracy. In: Benhabib S (eds) Democracy and difference. Contesting the boundaries of the political. Princeton University Press, New Jersey, USA.

8. Wheeland SA (2005) Creating effective teams: A guide for members and leaders. Sage Publications, California, USA

9. Woods PA (2004) Democratic leadership: drawing distinctions with distributed leadership. Journal Leadership in Education. 17: 3-26.

10. Yukl G (2010) Leadership in Organization. Pearson Education, Inc, India.

11. Cowden T, Cummings G, Profetto-McGrath J (2011) Leadership practices and staff nurses' intent to stay: a systematic review. J Nurs Manag 19: 461-477.

12. Kean S, Haycock-Stuart E, Baggaley S, Carson M (2011) Followers and the co-construction of leadership. J Nurs Manag 19: 507-516.

13. Cummings GG, MacGregor T, Davey M, Lee H, Wong CA, et al. (2010) Leadership styles and outcome patterns for the nursing workforce and work environment: a systematic review. Int J Nurs Stud 47: 363-385.

14. Patrick A, Laschinger HK, Wong C, Finegan J (2011) Developing and testing a new measure of staff nurse clinical leadership: the clinical leadership survey. $J$ Nurs Manag 19: 449-460.

15. Caldwell C, Dixon RD, Floyd LA, Chaudoin J, Post J, Cheokas G (2012) Transformative Leadership: Achieving Unparalleled Excellence. Journal Business Ethics 109: 175-187.

16. Sandberg J, Targam A (2007) Managing understanding in organizations. SAGE, London, UK.

17. Schreuder JA, Roelen CA, Van Zweeden NF, Jongsma D, Van der Klink JJ, et al. (2011) Leadership effectiveness and recorded sickness absence among nursing staff: a cross-sectional pilot study. J Nurs Manag 19: 585-595.

18. Josefsson K, Hansson M (2011) To lead and to be led in municipal elderly care in Sweden as perceived by registered nurses. J Nurs Manag 19: 498-506.
19. Kvale S, Brinkmann S (2009) InterViews: learning the craft of qualitative research interviewing. Sage Publications, Los Angeles, USA

20. Crossley ML (2002) 'Could you please pass one of those health leaflets along?': exploring health, morality and resistance through focus groups. Soc Sci Med 55: 1471-1483.

21. Thorne S (2008) Interpretive description. Left Coast Press, California, USA.

22. Kihlgren A, Forslund K, Fagerberg I (2006) Managements' perception of community nurses' decision-making processes when referring older adults to an emergency department. J Nurs Manag 14: 428-436.

23. Pearce CL (2007) The future of leadership development: The importance of identity, multi-level approaches, self-leadership, physical fitness, shared leadership, networking, creativity, emotions, spiritually and on-boarding processes. Human Resource Management Review 17: 355-359.

24. Casida J, Parker J (2011) Staff nurse perceptions of nurse manager leadership styles and outcomes. J Nurs Manag 19: 478-486.

25. Wong CA, Cummings GG (2007) The relationship between nursing leadership and patient outcomes: a systematic review. J Nurs Manag 15: 508-521.

26. Haycock-Stuart E, Kean S (2012) Does nursing leadership affect the quality of care in the community setting? J Nurs Manag 20: 372-381.

27. Sellgren SF, Ekvall G, Tomson G (2008) Leadership behaviour of nurse managers in relation to job satisfaction and work climate. J Nurs Manag 16 578-587.

28. Sørensen EE, Delmar C, Pedersen BD (2011) Leading nurses in dire straits: head nurses' navigation between nursing and leadership roles. J Nurs Manag 19: 421-430.

29. Wilhelmsson L (2006) Transformative Learning in Joint Leadership. Journal of Workplace Learning 18: 495-507.

30. Gustavsson B (2004) Revisiting the philosophical roots of practical knowledge In: Higgs J, Richardson B, Dahlgren M (eds), Developing practice knowledge for health sciences. Butterworth-Heinemann, Edinburgh, UK.

31. Cook MJ, Leathard HL (2004) Learning for clinical leadership. J Nurs Manag 12: $436-444$.

32. Ryle G (1949) The concept of mind. Hutchinson, London, UK

33. Polanyi M (1967) The tacit dimension. Routledge \& Kegan Paul, London.

34. Schön D (1987) Educating the Reflective Practitioner: Toward a New Design for Teaching and Learning in the Professions. Jossey-Bass Publisher, San Francisco, USA

35. Karsh B, Booske BC, Sainfort F (2005) Job and organizational determinants of nursing home employee commitment, job satisfaction and intent to turnover. Ergonomics 48: 1260-1281.

36. Lincoln Y, Guba E (1985) Naturalistic inquiry. Sage, New York, UK.

37. Creswell JW (2007) Qualitative inquiry \& research design: choosing among five approaches. SAGE, Thousand Oaks, California.

38. Sandelowski M (1994) The use of quotes in qualitative research. Res Nurs Health 17: 479-482. 